\title{
Prevalence and regional variation in meticillin- resistant Staphylococcus aureus (MRSA) in the USA and comparative in vitro activity of tigecycline, a glycylcycline antimicrobial
}

Correspondence

Debra A. Goff

debbie.goff@osumc.edu

Received 10 May 2006

Accepted 13 February 2007

\section{Debra A. Goff ${ }^{1}$ and Michael J. Dowzicky ${ }^{2}$}

\author{
${ }^{1}$ The Ohio State University Medical Center, Department of Pharmacy, Columbus, OH 43210, USA \\ ${ }^{2}$ Wyeth Pharmaceuticals, Collegeville, PA, USA
}

\begin{abstract}
The Tigecycline Evaluation and Surveillance Trial (T.E.S.T.) is a surveillance study established in 2004 to monitor the activity of tigecycline, the first glycylcycline, and comparator agents [ $\beta$ lactams (including penicillins, cephalosporins and carbapenems), glycopeptides, tetracyclines, fluoroquinolones and oxazolidinones] against Gram-positive and Gram-negative pathogens worldwide. This report examines 1692 isolates of Staphylococcus aureus collected in the continental United States between January 2004 and September 2005. Meticillin-resistant S. aureus (MRSA) accounted for $52.0 \%$ of isolates. Prevalence of MRSA by state ranged from $12.5 \%$ in New Hampshire to $100 \%$ in Kentucky. All isolates were susceptible to tigecycline, linezolid and vancomycin. In vitro, tigecycline was potent against both meticillin-susceptible $S$. aureus (MSSA) $\left(\mathrm{MIC}_{50}\right.$ and $\left.\mathrm{MIC}_{90}=0.12 \mu \mathrm{g} \mathrm{ml}^{-1}\right)$ and $\mathrm{MRSA}\left(\mathrm{MIC}_{50}=0.12 \mu \mathrm{g} \mathrm{m}^{-1}\right.$; $\mathrm{MIC}_{90}=0.25 \mu \mathrm{g} \mathrm{ml}^{-1}$ ). Only a single isolate was resistant to three or more antimicrobial classes. Ninety-six isolates $(5.7 \%)$ were susceptible to the complete antimicrobial panel.
\end{abstract}

\section{INTRODUCTION}

Staphylococcus aureus is an opportunistic pathogen and is the causative agent of infections such as bacteraemia, sepsis, toxic shock syndrome, bone and joint infection and skin and skin-structure infections (SSSIs), which can result in significant morbidity and mortality (Cunha, 2005; Padmanabhan \& Fraser, 2005; Weber, 2005). Meticillinresistant $S$. aureus (MRSA) isolates have been a source of serious infections in hospitals (healthcare-acquired MRSA; HA-MRSA) since the 1960s and are frequently resistant to other antimicrobial classes, complicating treatment and reducing therapeutic options (Padmanabhan \& Fraser, 2005).

Isolates of community-associated MRSA (CA-MRSA) have also been identified in recent years, which often possess fundamentally different genetic characteristics and risk factors from HA-MRSA. One important example is the Panton-Valentine leukocidin toxin gene, which has been associated with necrotizing pneumonia (Weber, 2005; Moran et al., 2005).

Abbreviations: clAl; complicated intra-abdominal infection; MRSA, meticillin-resistant Staphylococcus aureus; CA-MRSA, community-associated MRSA; HA-MRSA, healthcare-acquired MRSA; MSSA, meticillinsusceptible $S$. aureus; SSSI, skin and skin-structure infection.

All MIC testing was done locally following a standard protocol.
Future monitoring of the epidemiology of HA-MRSA and CA-MRSA will depend in part on microbial surveillance studies. These provide up-to-date information on the emergence, dissemination, frequency and consequences of microbial resistance and are essential tools in aiding the decision-making process for physicians (Koeth \& Miller, 2005). T.E.S.T. (the Tigecycline Evaluation and Surveillance Trial) is a global surveillance study initiated in 2004 to examine the in vitro activity of tigecycline and comparator agents against recent isolates of key Gramnegative and Gram-positive pathogens [including meticillin-susceptible $S$. aureus (MSSA) and MRSA] from hospitals and the community.

Tigecycline is the first of a new class of antimicrobial agents, the glycylcyclines, which are structurally derived from the tetracycline nucleus. Tigecycline possesses activity against Gram-positive and -negative pathogens, binding to the $30 \mathrm{~S}$ ribosomal subunit and inhibiting protein synthesis (Bouchillon et al., 2005). Tigecycline does not demonstrate co-resistance with known mechanisms of resistance, including tetracycline resistance (Bergeron et al., 1996). Tigecycline has in vitro activity against drug-resistant phenotypes including vancomycin-resistant enterococci (VRE), penicillin-resistant Streptococcus pneumoniae (PRSP), MSSA and MRSA and extended-spectrum $\beta$ lactamase (ESBL)-producing Escherichia coli and Klebsiella pneumoniae (Fritsche et al., 2005; Hoban et al., 2005). It is 
bacteriostatic against most pathogens, although bactericidal activity has been reported against Streptococcus pneumoniae and Haemophilus influenzae (Zinner, 2005).

This study reports on the relative prevalence of MRSA and MSSA and the occurrence of multidrug resistance (resistance to three or more antimicrobial classes) among $S$. aureus isolates collected in the continental United States as part of T.E.S.T. This report will also compare the activity of tigecycline and several comparator antimicrobials against these strains of MSSA and MRSA.

\section{METHODS}

Bacterial isolates. Consecutive isolates of $S$. aureus were collected from 72 centres in 38 states (Table 1) across the continental United States between January 2004 and September 2005. Each participating centre was requested to provide at least $25 \mathrm{~S}$. aureus isolates. All isolates were collected from patients aged 1 to 98 years with documented blood, respiratory tract, urine, skin, wound or body fluid infections or infections from other defined sources. Isolates from urine accounted for no more than $25 \%$ of isolates from any one centre. One isolate only was accepted per patient. All isolates were identified on-site by the participating laboratory. Laboratories International for Microbiology Studies, a division of International Health Management Associates, Inc. (Schaumburg, IL, USA), was responsible for organism collection, transport and identification confirmation as well as database development and management.

Antimicrobial susceptibility testing. Minimum inhibitory concentrations (MICs) were determined locally using Clinical and Laboratory Standards Institute (CLSI, formerly the NCCLS) -approved broth microdilution methodology (NCCLS, 2003). Antimicrobial agents included in the testing panel and the testing ranges used in this study (in $\mu \mathrm{g} \mathrm{ml}^{-1}$ ) are presented in Table 2. The MIC interpretive criterion for tigecycline (susceptible breakpoint $\leqslant 0.5 \mu \mathrm{g} \mathrm{ml}^{-1}$ ) was derived from the recent US Food and Drug Administration product insert for tigecycline. Determination of intermediate or resistant breakpoints is prevented by the current absence of clinical $S$. aureus isolates resistant to tigecycline (Wyeth Pharmaceuticals, 2005). S. aureus strains ATCC 25923 and ATCC 29213 were used for quality control of standardized laboratory procedures.

Multidrug resistance is defined for this report as resistance to three or more antimicrobial classes.

\section{RESULTS}

A total of 1692 isolates of $S$. aureus were collected across the continental United States during the study period. Of these, $879(52.0 \%)$ were identified as MRSA. Geographical distributions of $S$. aureus, MRSA and MSSA isolates are reported in Table 1. MRSA occurred infrequently in the participating hospital(s) in some states (i.e. $\leqslant 20 \%$ in NH, VT and VA) but was prevalent in others (i.e. all $25 \mathrm{~S}$. aureus isolates collected in KY were MRSA). Although MRSA accounted for $\geqslant 50 \%$ of $S$. aureus isolates in 21 states (IL, MI, OH, KS, ND, NE, DC, FL, GA, MD, NC, AL, $\mathrm{KY}, \mathrm{TN}, \mathrm{AR}, \mathrm{LA}, \mathrm{OK}, \mathrm{TX}, \mathrm{AZ}, \mathrm{NM}$ and WA), the proportion of MRSA and MSSA isolates is approximately equal in many states, with MRSA representing $40-60 \%$ of isolates in 25 states.
Table 1. Geographical distribution of Staphylococcus aureus, MSSA and MRSA collected across the continental United States between January 2004 and September 2005

\begin{tabular}{|c|c|c|c|}
\hline State & S. aureus $(n)$ & MSSA $(n)$ & MRSA $(n)$ \\
\hline \multicolumn{4}{|l|}{ New England } \\
\hline Connecticut (CT) & 24 & 13 & 11 \\
\hline Massachusetts (MA) & 40 & 27 & 13 \\
\hline New Hampshire (NH) & 24 & 21 & 3 \\
\hline Vermont (VT) & 25 & 21 & 4 \\
\hline \multicolumn{4}{|l|}{ Middle Atlantic } \\
\hline New Jersey (NJ) & 96 & 49 & 47 \\
\hline New York (NY) & 213 & 110 & 103 \\
\hline Pennsylvania (PA) & 24 & 14 & 10 \\
\hline \multicolumn{4}{|l|}{ East North Central } \\
\hline Illinois (IL) & 25 & 11 & 14 \\
\hline Indiana (IN) & 25 & 13 & 12 \\
\hline Michigan (MI) & 74 & 33 & 41 \\
\hline Ohio $(\mathrm{OH})$ & 141 & 68 & 73 \\
\hline Wisconsin (WI) & 22 & 13 & 9 \\
\hline \multicolumn{4}{|l|}{ West North Central } \\
\hline Kansas (KS) & 25 & 11 & 14 \\
\hline Minnesota (MN) & 25 & 16 & 9 \\
\hline Missouri (MO) & 25 & 15 & 10 \\
\hline North Dakota (ND) & 22 & 10 & 12 \\
\hline Nebraska (NE) & 25 & 10 & 15 \\
\hline \multicolumn{4}{|l|}{ South Atlantic } \\
\hline $\begin{array}{l}\text { District of Columbia } \\
\text { (DC) }\end{array}$ & 21 & 6 & 15 \\
\hline Florida (FL) & 66 & 16 & 50 \\
\hline Georgia (GA) & 91 & 31 & 60 \\
\hline Maryland (MD) & 45 & 18 & 27 \\
\hline North Carolina (NC) & 45 & 15 & 30 \\
\hline Virginia (VA) & 24 & 20 & 4 \\
\hline West Virginia (WV) & 25 & 14 & 11 \\
\hline \multicolumn{4}{|l|}{ East South Central } \\
\hline Alabama (AL) & 24 & 11 & 13 \\
\hline Kentucky (KY) & 25 & 0 & 25 \\
\hline Mississippi (MS) & 22 & 12 & 10 \\
\hline Tennessee (TN) & 62 & 27 & 35 \\
\hline \multicolumn{4}{|l|}{ West South Central } \\
\hline Arkansas (AR) & 22 & 11 & 11 \\
\hline Louisiana (LA) & 45 & 22 & 23 \\
\hline Oklahoma (OK) & 24 & 10 & 14 \\
\hline Texas (TX) & 68 & 28 & 40 \\
\hline \multicolumn{4}{|l|}{ Mountain } \\
\hline Arizona (AZ) & 40 & 12 & 28 \\
\hline New Mexico (NM) & 25 & 12 & 13 \\
\hline Utah (UT) & 25 & 15 & 10 \\
\hline \multicolumn{4}{|l|}{ Pacific } \\
\hline California (CA) & 68 & 46 & 22 \\
\hline Oregon (OR) & 45 & 23 & 22 \\
\hline Washington (WA) & 25 & 9 & 16 \\
\hline Totals & 1692 & 813 & 879 \\
\hline
\end{tabular}

Susceptibility data for all S. aureus isolates as well as MSSA and MRSA are presented in Table 3. All isolates were susceptible to tigecycline, linezolid and vancomycin. Minocycline was also highly active: $99.2 \%$ of isolates were 
Table 2. Antimicrobial testing panel and test ranges $\left(\mu \mathrm{g} \mathrm{ml}^{-1}\right)$ for $S$. aureus

\begin{tabular}{|llc|}
\hline Antimicrobial & \multicolumn{1}{c|}{ Class } & Test range \\
\hline Tigecycline (Tig) & Glycylcycline & $0.008-16$ \\
Amoxicillin/clavulanate & $\beta$-Lactam (penicillin) & $0.03-8$ \\
$\quad$ (Aug) & & \\
Ampicillin (Amp) & $\beta$-Lactam (penicillin) & $0.06-16$ \\
Penicillin (Pen) & $\beta$-Lactam (penicillin) & $0.06-8$ \\
Piperacillin/tazobactam & $\beta$-Lactam (penicillin) & $0.25-16$ \\
(Ppt) & & \\
Ceftriaxone (Cax) & $\beta$-Lactam (cephalosporin) & $0.03-64$ \\
Imipenem (Imp) & $\beta$-Lactam (carbapenem) & $0.12-16$ \\
Levofloxacin (Lvx) & Fluoroquinolone & $0.06-32$ \\
Linezolid (Lzd) & Oxazolidinone & $0.5-8$ \\
Minocycline (Min) & Tetracycline & $0.25-8$ \\
Vancomycin (Van) & Glycopeptide & $0.12-32$ \\
\hline
\end{tabular}

susceptible, including $99.3 \%$ of MRSA and $99.0 \%$ of MSSA isolates. Some $91.0 \%$ of all S. aureus isolates were susceptible to imipenem, although in the subset of MRSA isolates only $82.6 \%$ were susceptible by MIC criteria. Four agents (amoxicillin/clavulanate, piperacillin/tazobactam, levofloxacin and ceftriaxone) demonstrated susceptibilities by MIC criteria of between 40 and $90 \%$ against the complete panel of $S$. aureus isolates; against the subset of MRSA isolates, susceptibility to these agents was low $(<32 \%)$. For example, 696 (79.2\%) MRSA isolates across the United States were resistant to levofloxacin, ranging from $47.8 \%$ in LA to $100 \%$ in AZ (Table 4).

Tigecycline testing against all $S$. aureus isolates resulted in the lowest MICs reported in this study, with an $\mathrm{MIC}_{50}$ of $0.12 \mu \mathrm{g} \mathrm{ml}^{-1}$ and an $\mathrm{MIC}_{90}$ of $0.25 \mu \mathrm{g} \mathrm{ml}^{-1}$. Low tigecycline $\mathrm{MIC}_{50}$ and $\mathrm{MIC}_{90}$ results were also reported against the MSSA $\left(\mathrm{MIC}_{50}\right.$ and $\mathrm{MIC}_{90} 0.12 \mu \mathrm{g} \mathrm{ml}^{-1}$ ) and MRSA (MRSA MIC $50.12 \mu \mathrm{g} \mathrm{ml}^{-1}$; MIC $_{90} 0.25 \mu \mathrm{g} \mathrm{ml}^{-1}$ ) subsets. Minocycline testing produced an $\mathrm{MIC}_{50}$ of $\leqslant 0.25$ and an $\mathrm{MIC}_{90}$ of $0.5 \mu \mathrm{g} \mathrm{ml}^{-1}$ against all isolates. Minocycline was also active against both $S$. aureus subsets, resulting in an $\mathrm{MIC}_{50}$ and $\mathrm{MIC}_{90}$ of $\leqslant 0.25 \mu \mathrm{g} \mathrm{ml}^{-1}$ against MSSA and an $\mathrm{MIC}_{50}$ of $\leqslant 0.25 \mu \mathrm{g} \mathrm{ml}^{-1}$ and an $\mathrm{MIC}_{90}$ of $0.5 \mu \mathrm{g} \mathrm{ml}^{-1}$ against MRSA. Vancomycin was also active against $S$. aureus, with an $\mathrm{MIC}_{50}$ of $0.5 \mu \mathrm{g} \mathrm{ml}^{-1}$ and $\mathrm{MIC}_{90}$ of $1 \mu \mathrm{g} \mathrm{ml}^{-1}$ against MSSA and $\mathrm{MIC}_{50}$ and $\mathrm{MIC}_{90}$ of $1 \mu \mathrm{g} \mathrm{ml}^{-1}$ against MRSA. The linezolid $\mathrm{MIC}_{50}$ was $2 \mu \mathrm{g} \mathrm{ml}^{-1}$ against both MSSA and MRSA; its MIC $_{90}$ was $2 \mu \mathrm{g} \mathrm{ml}^{-1}$ for MSSA and $4 \mu \mathrm{g} \mathrm{ml}^{-1}$ for MRSA.

Considerable variation exists between national and state susceptibility/MIC data. For example, the $\mathrm{MIC}_{90}$ for imipenem against all $S$. aureus isolates across the country was $4 \mu \mathrm{g} \mathrm{ml}^{-1}$; however, nine states (IN, OH, ND, DC, FL, $\mathrm{NC}, \mathrm{LA}, \mathrm{UT}$ and WA) reported imipenem $\mathrm{MIC}_{90}$ values $\geqslant 2$ doubling dilutions higher than the national average, while 16 states (NH, VT, NJ, IL, KS, NE, GA, VA, WV, AL, $\mathrm{KY}, \mathrm{MS}, \mathrm{TN}, \mathrm{NM}, \mathrm{CA}$ and $\mathrm{OR}$ ) reported $\mathrm{MIC}_{90}$ values $\geqslant 2$ doubling dilutions lower than the national average (data not shown). This wide range was probably due to regional variations in MRSA occurrence, against which a substantially higher $\mathrm{MIC}_{90}$ for imipenem has been reported in this study $\left(16 \mu \mathrm{g} \mathrm{ml}^{-1}\right)$.

Only $96(5.7 \%)$ S. aureus isolates were susceptible to all antimicrobial agents tested; all were MSSA. Multidrug resistance (resistance to three or more antimicrobial classes) was noted in a single isolate in this study. This isolate was collected from a sputum sample collected from a 16-year-old female in New York. It was resistant to all $\beta$ lactams (amoxicillin/clavulanate, ampicillin, penicillin, piperacillin/tazobactam, ceftriaxone and imipenem), fluoroquinolones (levofloxacin) and tetracyclines (minocycline) but was susceptible to tigecycline (MIC $0.5 \mu \mathrm{g} \mathrm{ml}^{-1}$ ), linezolid $\left(2 \mu \mathrm{g} \mathrm{ml}^{-1}\right)$ and vancomycin $\left(2 \mu \mathrm{g} \mathrm{ml}^{-1}\right)$.

\section{DISCUSSION}

Isolates of $S$. aureus resistant to meticillin were first reported in 1961 and have been a common cause of outbreaks in hospitals since the 1970s (Cunha, 2005). By 2003, MRSA accounted for $59.5 \%$ of nosocomial S. aureus infections in intensive care units (ICUs) in the United States (National Nosocomial Infections Surveillance System, 2004). This ICU result is slightly higher than the MRSA prevalence of $52.0 \%$ reported among all hospital isolates in the United States from the T.E.S.T. study.

The three most active agents in vitro against MRSA identified in this study were tigecycline, vancomycin and linezolid, with $100 \%$ susceptibility reported for each. Recent reports of MRSA resistance to linezolid (Wilson et al., 2003; Anderegg et al., 2005; Peeters \& Sarria, 2005) and vancomycin (Bozdogan et al., 2003; Chang et al., 2003) highlight the importance of the development of new agents, such as tigecycline, for the appropriate treatment of infections where highly resistant pathogens are suspected or known.

Tigecycline has previously been shown to be highly active in vitro against $S$. aureus. Hoban et al. (2005), in an examination of T.E.S.T. database isolates collected globally in 2004, reported an $\mathrm{MIC}_{50}$ of $0.12 \mu \mathrm{g} \mathrm{ml}^{-1}$ and $\mathrm{MIC}_{90}$ of $0.25 \mu \mathrm{g} \mathrm{ml}^{-1}$ for tigecycline against both MRSA $(n=348)$ and MSSA ( $n=489$ ), with $98.9 \%$ of MRSA and $99.8 \%$ of MSSA isolates susceptible. Fritsche et al. (2004) reported an $\mathrm{MIC}_{50}$ of $0.25 \mu \mathrm{g} \mathrm{ml}^{-1}$ and an $\mathrm{MIC}_{90}$ of $0.5 \mu \mathrm{g} \mathrm{ml}^{-1}$ for tigecycline against oxacillin-susceptible $(n=3196)$ and -resistant $(n=1881)$ isolates of $S$. aureus in a clinical study of global isolates collected from patients with communityacquired respiratory tract and cutaneous infections. All isolates in this study were susceptible to tigecycline. Fritsche \& Jones (2004) showed similar activity for tigecycline against MSSA and MRSA recovered from nosocomial and community-acquired infections. In this study, 3498 isolates of $S$. aureus possessed an $\mathrm{MIC}_{50}$ of $0.25 \mu \mathrm{g} \mathrm{ml}^{-1}$ and an $\mathrm{MIC}_{90}$ of $0.5 \mu \mathrm{g} \mathrm{ml}^{-1}$, with no 
Table 3. Antimicrobial activity of tigecycline and comparator antimicrobial agents against clinical isolates of $S$. aureus $(n=1692)$, MSSA $(n=813)$ and MRSA $(n=879)$ across the continental United States

$\% \mathrm{~S}$ represents the percentage of susceptible isolates (susceptibility to $\beta$-lactam antimicrobials indicates in vitro activity only). \%R indicates the percentage of resistant isolates.

\begin{tabular}{|c|c|c|c|c|c|c|}
\hline \multirow[t]{2}{*}{ Drug } & \multirow[t]{2}{*}{ Isolates } & \multicolumn{2}{|c|}{$\operatorname{MIC}\left(\mu \mathrm{g} \mathrm{ml}^{-1}\right)$} & \multirow[t]{2}{*}{ MIC range } & \multirow[t]{2}{*}{$\% \mathrm{~S}$} & \multirow[t]{2}{*}{$\% \mathrm{R}$} \\
\hline & & $\mathrm{MIC}_{50}$ & $\mathrm{MIC}_{90}$ & & & \\
\hline \multirow{3}{*}{ Tigecycline } & S. aureus & 0.12 & 0.25 & $0.015-0.5$ & 100 & 0.0 \\
\hline & MSSA & 0.12 & 0.12 & $0.015-0.5$ & 100 & 0.0 \\
\hline & MRSA & 0.12 & 0.25 & $0.03-0.5$ & 100 & 0.0 \\
\hline \multirow[t]{3}{*}{ Amoxicillin/clavulanate } & S. aureus & 2 & $\geqslant 16$ & $\leqslant 0.03-\geqslant 16$ & 61.1 & 38.9 \\
\hline & MSSA & 1 & 2 & $\leqslant 0.03-4$ & 100 & 0.0 \\
\hline & MRSA & 8 & $\geqslant 16$ & $1-\geqslant 16$ & 25.1 & 74.9 \\
\hline \multirow[t]{3}{*}{ Ampicillin } & S. aureus & 16 & $\geqslant 32$ & $\leqslant 0.06-\geqslant 32$ & 7.6 & 92.4 \\
\hline & MSSA & 4 & $\geqslant 32$ & $\leqslant 0.06-\geqslant 32$ & 15.9 & 84.1 \\
\hline & MRSA & $\geqslant 32$ & $\geqslant 32$ & $0.5-\geqslant 32$ & 0.0 & 100 \\
\hline \multirow[t]{3}{*}{ Penicillin } & S. aureus & $\geqslant 16$ & $\geqslant 16$ & $\leqslant 0.06-\geqslant 16$ & 6.7 & 93.3 \\
\hline & MSSA & 8 & $\geqslant 16$ & $\leqslant 0.06-\geqslant 16$ & 13.9 & 86.1 \\
\hline & MRSA & $\geqslant 16$ & $\geqslant 16$ & $0.25-\geqslant 16$ & 0.0 & 100 \\
\hline \multirow[t]{3}{*}{ Piperacillin/tazobactam } & S. aureus & 4 & $\geqslant 32$ & $\leqslant 0.25-\geqslant 32$ & 64.6 & 35.4 \\
\hline & MSSA & 1 & 2 & $\leqslant 0.25-8$ & 100 & 0.0 \\
\hline & MRSA & 16 & $\geqslant 32$ & $1-\geqslant 32$ & 31.9 & 68.1 \\
\hline \multirow[t]{3}{*}{ Ceftriaxone } & S. aureus & 16 & $\geqslant 128$ & $0.12-\geqslant 128$ & 46.7 & 21.5 \\
\hline & MSSA & 4 & 4 & $0.12-32$ & 96.9 & 0.0 \\
\hline & MRSA & 32 & $\geqslant 128$ & $8-\geqslant 128$ & 0.2 & 41.3 \\
\hline \multirow[t]{3}{*}{ Imipenem } & S. aureus & 0.25 & 4 & $\leqslant 0.12-\geqslant 32$ & 91.0 & 7.1 \\
\hline & MSSA & 0.25 & 0.25 & $\leqslant 0.12-2$ & 100 & 0.0 \\
\hline & MRSA & 0.5 & 16 & $\leqslant 0.12-\geqslant 32$ & 82.6 & 13.7 \\
\hline \multirow[t]{3}{*}{ Levofloxacin } & S. aureus & 0.5 & $\geqslant 64$ & $\leqslant 0.06-\geqslant 64$ & 51.7 & 46.0 \\
\hline & MSSA & 0.12 & 4 & $\leqslant 0.06-\geqslant 64$ & 87.6 & 10.1 \\
\hline & MRSA & 16 & $\geqslant 64$ & $\leqslant 0.06-\geqslant 64$ & 18.5 & 79.2 \\
\hline \multirow[t]{3}{*}{ Linezolid } & S. aureus & 2 & 4 & $\leqslant 0.5-4$ & 100 & 0.0 \\
\hline & MSSA & 2 & 2 & $\leqslant 0.5-4$ & 100 & 0.0 \\
\hline & MRSA & 2 & 4 & $\leqslant 0.5-4$ & 100 & 0.0 \\
\hline \multirow[t]{3}{*}{ Minocycline } & S. aureus & $\leqslant 0.25$ & 0.5 & $\leqslant 0.25-\geqslant 16$ & 99.2 & 0.1 \\
\hline & MSSA & $\leqslant 0.25$ & $\leqslant 0.25$ & $\leqslant 0.25-8$ & 99.0 & 0.0 \\
\hline & MRSA & $\leqslant 0.25$ & 0.5 & $\leqslant 0.25-\geqslant 16$ & 99.3 & 0.1 \\
\hline \multirow[t]{3}{*}{ Vancomycin } & S. aureus & 1 & 1 & $\leqslant 0.12-4$ & 100 & 0.0 \\
\hline & MSSA & 0.5 & 1 & $\leqslant 0.12-4$ & 100 & 0.0 \\
\hline & MRSA & 1 & 1 & $0.25-4$ & 100 & 0.0 \\
\hline
\end{tabular}

differences in MIC noted between MSSA or MRSA subgroups. All isolates were inhibited by tigecycline at $\leqslant 1 \mu \mathrm{g} \mathrm{ml}^{-1}$.

Recent comparative studies have also demonstrated the clinical efficacy of tigecycline in complicated SSSIs and complicated intra-abdominal infections (cIAIs). In a summary of in vitro data from Phase 3 clinical trials in cSSSIs and cIAIs, Bradford et al. (2005) compared the in vitro activity of tigecycline with that of several other antimicrobial agents. Tigecycline was the most active antimicrobial agent in this study, with an $\mathrm{MIC}_{90}$ of $0.25 \mu \mathrm{g} \mathrm{ml}^{-1}$ reported for MSSA and MRSA isolates collected from patients with either SSSIs or IAIs. Minocycline was also highly active against MRSA in this study, but in a direct comparison between these two agents, 11 minocycline-resistant MRSA isolates were identified that were susceptible to tigecycline at low concentrations $\left(\leqslant 0.5 \mu \mathrm{g} \mathrm{ml}^{-1}\right.$ ) (Bradford et al., 2005).

McAleese et al. (2005) have recently reported a serial passage study in which reduced susceptibility to tigecycline was selected among two strains of $S$. aureus. These strains were grown in increasing concentrations of tigecycline over a period of 16 days, after which MICs increased by 16 -fold for S. aureus strain $\mathrm{N} 315$ and 32-fold for strain Mu3. After passage, both strains showed more than 100-fold increases in expression of the gene cluster mepRAB, which encodes the transcription regulator gene mepR, the efflux pump gene $m e p A$ and a third protein of unknown function (mepB). 
Table 4. Prevalences of MRSA $(n=879)$ and fluoroquinolone (FQ)-resistant MRSA $(n=696)$ by state collected between January 2004 and September 2005

\begin{tabular}{|c|c|c|c|c|c|}
\hline \multirow[t]{2}{*}{ State } & \multirow[t]{2}{*}{$\begin{array}{c}\text { S. aureus } \\
\text { isolates }(n)\end{array}$} & \multicolumn{2}{|c|}{$\begin{array}{c}\text { MRSA } \\
\text { isolates }\end{array}$} & \multicolumn{2}{|c|}{$\begin{array}{l}\text { FQ-resist- } \\
\text { ant MRSA } \\
\text { isolates }\end{array}$} \\
\hline & & $n$ & $\%$ & $n$ & $\%^{*}$ \\
\hline \multicolumn{6}{|c|}{ New England } \\
\hline $\mathrm{CT}$ & 24 & 11 & 45.8 & 10 & 90.9 \\
\hline MA & 40 & 13 & 32.5 & 9 & 69.2 \\
\hline $\mathrm{NH}$ & 24 & 3 & 12.5 & 3 & - \\
\hline VT & 25 & 4 & 16.0 & 3 & - \\
\hline \multicolumn{6}{|c|}{ Middle Atlantic } \\
\hline NJ & 96 & 47 & 49.0 & 44 & 93.6 \\
\hline NY & 213 & 103 & 48.4 & 94 & 91.3 \\
\hline PA & 24 & 10 & 41.7 & 7 & 70.0 \\
\hline \multicolumn{6}{|c|}{ East North Central } \\
\hline IL & 25 & 14 & 56.0 & 11 & 78.6 \\
\hline IN & 25 & 12 & 48.0 & 9 & 75.0 \\
\hline MI & 74 & 41 & 55.4 & 30 & 73.2 \\
\hline $\mathrm{OH}$ & 141 & 73 & 51.8 & 55 & 75.3 \\
\hline WI & 22 & 9 & 40.9 & 9 & - \\
\hline \multicolumn{6}{|c|}{ West North Central } \\
\hline KS & 25 & 14 & 56.0 & 13 & 92.9 \\
\hline MN & 25 & 9 & 36.0 & 6 & - \\
\hline $\mathrm{MO}$ & 25 & 10 & 40.0 & 8 & 80.0 \\
\hline ND & 22 & 12 & 54.5 & 9 & 75.0 \\
\hline NE & 25 & 15 & 60.0 & 12 & 80.0 \\
\hline \multicolumn{6}{|c|}{ South Atlantic } \\
\hline DC & 21 & 15 & 71.4 & 14 & 93.3 \\
\hline FL & 66 & 50 & 75.8 & 38 & 76.0 \\
\hline GA & 91 & 60 & 65.9 & 44 & 73.3 \\
\hline MD & 45 & 27 & 60.0 & 24 & 88.9 \\
\hline $\mathrm{NC}$ & 45 & 30 & 66.7 & 27 & 90.0 \\
\hline VA & 24 & 4 & 16.7 & 3 & - \\
\hline WV & 25 & 11 & 44.0 & 10 & 90.9 \\
\hline \multicolumn{6}{|c|}{ East South Central } \\
\hline $\mathrm{AL}$ & 24 & 13 & 54.2 & 11 & 84.6 \\
\hline KY & 25 & 25 & 100 & 18 & 72.0 \\
\hline MS & 22 & 10 & 45.5 & 5 & 50.0 \\
\hline TN & 62 & 35 & 56.5 & 26 & 74.3 \\
\hline \multicolumn{6}{|c|}{ West South Central } \\
\hline $\mathrm{AR}$ & 22 & 11 & 50.0 & 8 & 72.7 \\
\hline LA & 45 & 23 & 51.1 & 11 & 47.8 \\
\hline OK & 24 & 14 & 58.3 & 8 & 57.1 \\
\hline TX & 68 & 40 & 58.8 & 25 & 62.5 \\
\hline \multicolumn{6}{|c|}{ Mountain } \\
\hline $\mathrm{AZ}$ & 40 & 28 & 70.0 & 28 & 100 \\
\hline NM & 25 & 13 & 52.0 & 12 & 92.3 \\
\hline UT & 25 & 10 & 40.0 & 9 & 90.0 \\
\hline \multicolumn{6}{|c|}{ Pacific } \\
\hline CA & 68 & 22 & 32.4 & 19 & 86.4 \\
\hline OR & 45 & 22 & 48.9 & 12 & 54.5 \\
\hline WA & 25 & 16 & 64.0 & 12 & 75.0 \\
\hline
\end{tabular}

${ }^{*}$ Calculated as percentage of MRSA isolates for states with $\geqslant 10$ MRSA isolates only.
Although several antimicrobial agents possess good in vitro activity against MRSA, most are inactive or only sporadically active against HA-MRSA in vivo. According to Cunha (2005), the list of antimicrobial agents with in vivo activity against MRSA is short, including only quinupristin/ dalfopristin, minocycline, daptomycin, linezolid and vancomycin (of these, only daptomycin, linezolid and vancomycin have MRSA indications). These agents are active against HA-MRSA, however; possible treatment options for CA-MRSA include clindamycin and trimethoprim/sulfamethoxazole. Recent clinical studies have shown that tigecycline also demonstrates a high degree of in vivo activity against $S$. aureus, both MSSA and MRSA. EllisGrosse et al. (2005) reported tigecycline microbiological eradication rates of 78.1 and $88.8 \%$ against MRSA $(n=32)$ and MSSA ( $n=134)$, respectively, among medically evaluable patients with SSSIs at the test-of-cure visit; patients treated with vancomycin/aztreonam reported eradication rates of $75.8 \%$ for MRSA $(n=33)$ and $90.8 \%$ for MSSA $(n=120)$. Similarly, Babinchak et al. (2005) recently showed equivalent microbiological eradication at test-ofcure visit among patients treated with tigecycline $(92.9 \%)$ or imipenem/cilastatin $(91.7 \%)$ for cIAIs not infected with MRSA.

Resistance to meticillin among nosocomial $S$. aureus isolates is imparted through acquisition of a genetic element, the staphylococcal cassette chromosome mecA (SCCmecA), which occurs in several forms. Types I to III impart resistance to $\beta$-lactam antimicrobials, while types II and III also impart resistance to numerous non- $\beta$-lactam antimicrobials (Padmanabhan \& Fraser, 2005; Katayama et al., 2000). Risk factors associated with the acquisition of nosocomial MRSA infections include previous hospitalization, increased length of hospital stay, previous exposure to antimicrobial agents (especially fluoroquinolones), enteral feeding and/or surgery (Graffunder \& Venezia, 2002).

Reports of infections caused by MRSA have begun to emerge in recent years among patients not previously exposed to nosocomial MRSA risk factors (Boyce, 2005). Isolates of CA-MRSA possess a novel cassette chromosome, SCCmecA type IV, which is smaller than that found in nosocomial isolates and can be transferred horizontally between isolates (Daum et al., 2002). It is dominated by the ccrAB2 allotype, which is prevalent among emerging community-acquired MRSA strains compared with the less common ccrAB4 allotype (Oliveira et al., 2006). CA-MRSA isolates are typically susceptible to more antimicrobials than HA-MRSA, including clindamycin, trimethoprim/sulfamethoxazole and the aminoglycosides. CA-MRSA also possesses different gene profiles, including Panton-Valentine leukocidin, which can result in increased toxicity (Stevenson et al., 2005). Although the name CAMRSA refers to colonization or infection in the community rather than actual acquisition (Salgado et al., 2003), CAMRSA strains are often derived from isolates picked up in healthcare facilities on previous visits or through contact with other individuals who have previously been exposed 
to HA-MRSA strains. The ability of CA-MRSA to transfer its SCCmecA IV gene horizontally might eventually result in the appearance of SCCmecA IV among HA-MRSA, making these strains even more difficult to distinguish in the future.

MRSA infections can be problematic to treat compared with MSSA infections in part because of the potentially enhanced virulence of MRSA, potentially decreased efficacy of vancomycin against MRSA and/or delays in initiating appropriate antimicrobial therapy (Cosgrove et al., 2003). Engemann et al. (2003) showed that MRSA SSSI patients had significantly longer median durations of hospital stay ( 8 vs 5 days; $P<0.001$ ) and significantly higher mortality $(20.7$ vs $6.7 \% ; P<0.001)$ than SSSI patients infected with MSSA. Treatment cost among MRSA patients can also be higher compared with MSSA patients (MRSA mean cost $=\$ 118415$; MSSA mean cost $=\$ 73165)$. Similarly, Cosgrove et al. (2003) reported a significant increase in mortality associated with MRSA infection compared with MSSA infection $(\mathrm{OR}=1.93 ; P<0.001)$ in a pooled analysis of 31 studies involving $S$. aureus bacteraemia.

Isolates of MRSA are commonly resistant to multiple antimicrobials, particularly members of the $\beta$-lactam family (Chen \& Huang, 2005). The selection of empirical therapy for the treatment of suspected MRSA infection should thus be based on as much clinical information as possible, including the presence of coexisting illness, prior antimicrobial therapy, duration of hospitalization, knowledge of local MRSA incidence and/or evidence of patient colonization (Haddadin et al., 2002). The high prevalence of MRSA reported here calls for extreme caution before commencing empirical therapy for any infection potentially caused by MRSA.

Prevalence of MRSA in those hospitals that submitted isolates varied widely by state in this study, ranging from $12.5 \%(3 / 24)$ in NH to $100 \%(25 / 25)$ in KY. Regions with high MRSA prevalences may be indicative of localized clonal MRSA outbreaks, as reported previously both in hospitals (Young et al., 2004) and in the community (Stemper et al., 2004). Such outbreaks are usually identified using pulsed-field gel electrophoresis, multi-locus sequence typing and/or staphylococcal cassette chromosome mec typing to identify genetically related clonal complexes (Gomes et al., 2005). Genotyping is not currently implemented in the T.E.S.T. study; its introduction would undoubtedly enhance its contribution to epidemiological investigations.

This report has shown (using imipenem as an example) that MRSA susceptibility data can vary widely between different states. MIC data for $\beta$-lactams against MRSA must be regarded with caution, as several $\beta$-lactams (i.e. penicillins, carbapenems, cephems, $\beta$-lactam/ $\beta$-lactamase inhibitor combinations) can provide false-positive susceptibility results against MRSA isolates that are not clinically effective (CLSI, 2005). Laboratory-derived MIC values may thus not accurately reflect clinical treatment options for
MRSA infections. Increasing resistance to established antiMRSA agents such as linezolid and vancomycin confirms the importance of the development of new antimicrobial agents that are effective against resistant organisms. The excellent in vitro activity of tigecycline against MSSA and MRSA could make it an important tool in the empirical (and targeted) therapy of nosocomial and community infections caused by resistant pathogens such as MRSA.

\section{ACKNOWLEDGEMENTS}

The authors wish to acknowledge the staff of International Health Management Associates, Inc., Schaumburg, IL, USA, for their coordination of the T.E.S.T. study. This study was funded by Wyeth Pharmaceuticals.

\section{REFERENCES}

Anderegg, T. R., Sader, H. S., Fritsche, T. R., Ross, J. E. \& Jones, R. N. (2005). Trends in linezolid susceptibility patterns: report from the 2002-2003 worldwide Zyvox Annual Appraisal of Potency and Spectrum (ZAAPS) Program. Int J Antimicrob Agents 26, 13-21.

Babinchak, T., Ellis-Grosse, E., Dartois, N., Rose, G. M. \& Loh, E. (2005). The efficacy and safety of tigecycline for the treatment of complicated intra-abdominal infections: analysis of pooled clinical trial data. The Tigecycline 301 and 306 Study Groups. Clin Infect Dis 41, S354-S367.

Bergeron, J., Ammirati, M., Danley, D., James, L., Norcia, M., Retsema, J., Strick, C. A., Su, W.-G., Sutcliffe, J. \& Wondrack, L. (1996). Glycylcyclines bind to the high-affinity tetracycline ribosomal binding site and evade Tet(M)- and Tet(O)-mediated ribosomal protection. Antimicrob Agents Chemother 40, 2226-2228.

Bouchillon, S. K., Hoban, D. J., Johnson, B. M., Johnson, J. L., Hsiung, A. \& Dowzicky, M. J. (2005). In vitro activity of tigecycline against 3989 Gram-negative and Gram-positive clinical isolates from the United States Tigecycline Evaluation and Surveillance Trial (T.E.S.T. Program; 2004). Diagn Microbiol Infect Dis 52, 173-179.

Boyce, J. M. (2005). Meticillin-resistant Staphylococcus aureus: USA. Lancet Infect Dis 5, 653-654.

Bozdogan, B., Esel, D., Whitener, C., Browne, F. A. \& Appelbaum, P. C. (2003). Antibacterial susceptibility of a vancomycin-resistant Staphylococcus aureus strain isolated at the Hershey Medical Center. J Antimicrob Chemother 52, 864-868.

Bradford, P. A., Weaver-Sands, D. T. \& Petersen, P. J. (2005). In vitro activity of tigecycline against isolates from patients enrolled in Phase 3 clinical trials of treatment for complicated skin and skin-structure infections and complicated intra-abdominal infections. Clin Infect Dis 41, S315-S332.

Chang, S., Sievert, D. M., Hageman, J. C., Boulton, M. L., Tenover, F. C., Downes, F. P., Shah, S., Rudrik, J. T., Pupp, G. R. \& other authors (2003). Infection with vancomycin-resistant Staphylococcus aureus containing the vanA resistance gene. N Engl J Med 348, 1342-1347.

Chen, C.-J. \& Huang, Y.-C. (2005). Community-acquired methicillinresistant Staphylococcus aureus in Taiwan. J Microbiol Immunol Infect 38, 376-382.

CLSI (2005). Performance standard for antimicrobial susceptibility testing, document M100-S15. Wayne, PA: Clinical and Laboratory Standards Institute.

Cosgrove, S. E., Sakoulas, G., Perencevich, E. N., Schwaber, M. J., Karchmer, A. W. \& Carmeli, Y. (2003). Comparison of mortality 
associated with methicillin-resistant and methicillin-susceptible Staphylococcus aureus bacteremia: a meta-analysis. Clin Infect Dis 36, 53-59.

Cunha, B. A. (2005). Methicillin-resistant Staphylococcus aureus: clinical manifestations and antimicrobial therapy. Clin Microbiol Infect 11 (Suppl. 4), 33-42.

Daum, R. S., Ito, T., Hiramatsu, K., Hussain, F., Mongkolrattanothai, K., Jamklang, M. \& Boyle-Vavra, S. (2002). A novel methicillin-resistance cassette in community-acquired methicillin-resistant Staphylococcus aureus isolates of diverse genetic backgrounds. J Infect Dis $\mathbf{1 8 6}$ 1344-1347.

Ellis-Grosse, E. J., Babinchak, T., Dartois, N., Rose, G. \& Loh, E. (2005). The efficacy and safety of tigecycline in the treatment of skin and skin-structure infections: results of 2 double-blind Phase 3 comparison studies with vancomycin-aztreonam. The Tigecycline 300 and 305 cSSSI Study Groups. Clin Infect Dis 41, S341-S353.

Engemann, J. J., Carmeli, Y., Cosgrove, S. E., Fowler, V. G., Bronstein, M. Z., Trivette, S. L., Briggs, J. P., Sexton, D. J. \& Kaye, K. S. (2003). Adverse clinical and economic outcomes attributable to methicillin resistance among patients with Staphylococcus aureus surgical site infection. Clin Infect Dis 36, 592-598.

Fritsche, T. R. \& Jones, R. N. (2004). Antimicrobial activity of tigecycline (GA-936) tested against 3498 recent isolates of Staphylococcus aureus recovered from nosocomial and communityacquired infections. Int J Antimicrob Agents 24, 567-571.

Fritsche, T. R., Kirby, J. T. \& Jones, R. N. (2004). In vitro activity of tigecycline (GAR-936) tested against 11,859 recent clinical isolates associated with community-acquired respiratory tract and Grampositive cutaneous infections. Diagn Microbiol Infect Dis 49, 201-209.

Fritsche, T. R., Sader, H. S., Stilwell, M. G., Dowzicky, M. J. \& Jones, R. N. (2005). Potency and spectrum of tigecycline tested against an international collection of bacterial pathogens associated with skin and soft tissue infections (2000-2004). Diagn Microbiol Infect Dis 52, 195-201.

Gomes, A. R., Vinga, S., Zavolan, M. \& de Lencastre, H. (2005). Analysis of the genetic variability of virulence-related loci in epidemic clones of methicillin-resistant Staphylococcus aureus. Antimicrob Agents Chemother 49, 366-379.

Graffunder, E. M. \& Venezia, R. A. (2002). Risk factors associated with nosocomial methicillin-resistant Staphylococcus aureus (MRSA) infection including previous use of antimicrobials. J Antimicrob Chemother 49, 999-1005.

Haddadin, A. S., Fappiano, S. A. \& Lipsett, P. A. (2002). Methicillin resistant Staphylococcus aureus (MRSA) in the intensive care unit. Postgrad Med J 78, 385-392.

Hoban, D. J., Bouchillon, S. K., Johnson, B. M., Johnson, J. L. \& Dowzicky, M. J. (2005). In vitro activity of tigecycline against 6792 Gram-negative and Gram-positive clinical isolates from the global Tigecycline Evaluation and Surveillance Trial (T.E.S.T. Program, 2004). Diagn Microbiol Infect Dis 52, 215-227.

Katayama, Y., Ito, T. \& Hiramatsu, K. (2000). A new class of genetic element, staphylococcus cassette chromosome mec, encodes methicillin resistance in Staphylococcus aureus. Antimicrob Agents Chemother 44, 1549-1555.
Koeth, L. M. \& Miller, L. A. (2005). Evolving concepts of pharmaceutical company-sponsored surveillance studies. Clin Infect Dis 41 (Suppl. 4), S279-S282.

McAleese, F., Petersen, P., Ruzin, A., Dunman, P. M., Murphy, E., Projan, S. J. \& Bradford, P. A. (2005). A novel MATE family efflux pump contributes to the reduced susceptibility of laboratory-derived Staphylococcus aureus mutants to tigecycline. Antimicrob Agents Chemother 49, 1865-1871.

Moran, G. J., Amii, R. N., Abrahamian, F. M. \& Talan, D. A. (2005). Methicillin-resistant Staphylococcus aureus in community-acquired skin infections. Emerg Infect Dis 11, 928-930.

National Nosocomial Infections Surveillance System (2004). National Nosocomial Infections Surveillance (NNIS) System Report, data summary from January 1992 through June 2004, issued October 2004. Am J Infect Control 32, 470-485.

NCCLS (2003). Methods for dilution antimicrobial susceptibility tests for bacteria that grow aerobically, document M7-A6. Wayne, PA: National Committee for Clinical Laboratory Standards.

Oliveira, D. C., Milheiriço, C. \& de Lencastre, H. (2006). Redefining a structural variant of staphylococcal cassette chromosome mec, SCCmec type VI. Antimicrob Agents Chemother 50, 3457-3459.

Padmanabhan, R. A. \& Fraser, T. G. (2005). The emergence of methicillin-resistant Staphylococcus aureus in the community. Cleve Clin J Med 72, 235-241.

Peeters, M. J. \& Sarria, J. C. (2005). Clinical characteristics of linezolid-resistant Staphylococcus aureus infections. Am J Med Sci 330, 102-104.

Salgado, C. D., Farr, B. M. \& Calfee, D. P. (2003). Communityacquired methicillin-resistant Staphylococcus aureus: a meta-analysis of prevalence and risk factors. Clin Infect Dis 36, 131-139.

Stemper, M. E., Shukla, S. K. \& Reed, K. D. (2004). Emergence and spread of community-associated methicillin-resistant Staphylococcus aureus in rural Wisconsin, 1989 to 1999. J Clin Microbiol 42, 5673-5680.

Stevenson, K. B., Searle, K., Stoddard, G. J. \& Samore, M. H. (2005). Methicillin-resistant Staphylococcus aureus and vancomycin-resistant enterococci in rural communities, western United States. Emerg Infect Dis 11, 895-903.

Weber, J. T. (2005). Community-associated methicillin-resistant Staphylococcus aureus. Clin Infect Dis 41, S269-S272.

Wilson, P., Andrews, J. A., Charlesworth, R., Walesby, R., Singer, M., Farrell, D. J. \& Robbins, M. (2003). Linezolid resistance in clinical isolates of Staphylococcus aureus. J Antimicrob Chemother 51, 186-188.

Wyeth Pharmaceuticals (2005). Tygacil product insert. Philadelphia: Wyeth Pharmaceuticals.

Young, L. S., Perdreau-Remington, F. \& Winston, L. G. (2004). Clinical, epidemiologic, and molecular evaluation of a clonal outbreak of methicillin-resistant Staphylococcus aureus infection. Clin Infect Dis 38, 1075-1083.

Zinner, S. H. (2005). Overview of antibiotic use and resistance: setting the stage for tigecycline. Clin Infect Dis 41, S289-S292. 